\title{
Investigating Attitudes of Sports Science Faculty Students Towards Scientific Research
}

\author{
Fuat Erduğan ${ }^{1}$ \\ ${ }^{1}$ Kırkpınar Faculty of Sports Science, Trakya University, Edirne, Turkey \\ Correspondence: Fuat Erduğan, Faculty of Sports Science, Trakya University, Balkan Campus, Edirne, Turkey. \\ E-mail: fuaterdugan@gmail.com
}

Received: March 12, 2020

Accepted: April 25, $2020 \quad$ Online Published: June 25, 2020

doi:10.5539/ies.v13n7p122

URL: https://doi.org/10.5539/ies.v13n7p122

\begin{abstract}
The purpose of this study was to investigate the attitudes of Sports science faculty students towards scientific research. The sample of this study consisted of 360 Sports science faculty students receiving pedagogical formation at Trakya, Iğdır, Recep Tayyip Erdoğan, Siirt, Çanakkale Onsekiz Mart University in Turkey. A demographic features form developed by researcher for determining the demographical features of participants and the 'Scale of Attitudes towards Scientific Research' developed by Korkmaz, Şahin, and Yeşil (2011) were used as a data collection tool. For the comparison of quantitative continuous data between two independent groups' t-test, and for the comparison of quantitative data between groups a One Way Anova test was used for data analysis. As a complementary Post-hoc analysis; the Tukey test was used to determine the differences after the Anova test. As a result, Sports science faculty students were determined to have different attitudes towards scientific research in terms of several variables. However, participants who wanted to become an academician were determined to have positive attitudes towards scientific research and researchers.
\end{abstract}

Keywords: attitude towards scientific research, sports science faculty, student

\section{Introduction}

Scientific research is carried out on theoretical and experimental levels and needs to be planned and organized before practicing. Courses related to scientific research methods are seen in the curriculums of Bachelors's and graduate levels at universities. Nowadays there has been an increasing number of studies related to attitudes of students from different disciplines towards scientific research. Particularly, student attitudes towards scientific research on university-level became significant among the population who intended to become scholars. Scientific research has an important place in daily life. Many of the inventions seen today are based on results from scientific research. These can be counted from finding cures for diseases to developments in technology (Shaukat et al., 2014). To take advantage of scientific research, researchers should have the necessary equipment and research skills and it is important to acknowledge the place of science in social life. Moreover, scientific research method courses should be taught to develop an attitude towards scientific research during formal education stages of students especially for those who will participate in scientific research in the future (Çelik et al., 2014). The term 'attitude' was first seen in the social psychology field and according to Allport (1935), attitude is defined as an emotional and mental readiness which have directive or dynamic influence on individual's behaviors against objects and states that she/he is interested as a result of his/her experiences. In several studies attitude was defined as the skill of positive or negative reactions against a certain object (Zan \& Di Martino, 2008). In retrospect, sports science as a science discipline goes back to ancient Greece. There were ancient writings concerning how to improve human health (Berryman \& Park, 1992). Today, scientific research is being practiced in sports sciences as in other scientific research fields. For this reason, research in sports science is important for the development of exercise and sports sciences in the world and Turkey. When viewed from this aspect this study revealed the attitudes of sports science faculty students towards scientific research and may guide lecturers and teaching staff to encourage them for having positive attitudes towards scientific research in sports science. In literature, it can be seen that sample groups of studies related to attitudes towards scientific research consisted of certain departments (Turkish teaching students, Science teaching students, education faculty-student, etc.) of universities (İlhan, Çelik, \& Aslan 2016; Shaukat et al., 2014; Polat, 2014). According to several study results to determine attitudes towards scientific research, in general, students were revealed to have negative or midlevel attitudes towards scientific 
research (Biçer, Bozkırl1, \& Er, 2013; Polat, 2014). Scientific research is difficult and challenging for students (Adams and, Holcomb, 1986). Furthermore, students don't know the importance of scientific research in their future careers (Shaukat et al., 2014). In literature research, no study was found discussing attitudes of sports science faculty students towards scientific research. In this respect, the purpose of this study was to reveal the attitudes of sports science faculty students towards scientific research. This research may contribute to help students for developing better attitudes towards scientific research and also may guide lecturers and teaching staff at sports science faculties in guiding students towards scientific research in a positive way. The purpose of this study was to investigate the attitudes of sports science faculty students towards scientific research.

\section{Method}

In this section, the model, population and sample, data collection tools, data collection, and information related to statistical analysis of data obtained will be explained.

\subsection{Study Group}

The sample and population of this study consisted of 360 sports science faculty students ( $\mathrm{n}=208$ male, 152 female) from the university of Trakya, Iğdır, Recep Tayyip Erdoğan, Siirt, and Çanakkale Onsekiz Mart who have been receiving pedagogical formation simultaneously.

\subsection{Sample Size and Sampling Procedures}

The participants of this study were selected through a random sampling and accepted to participate in this research voluntarily. 360 voluntary students from different universities have participated in this research in Edirne, Iğdır, Rize, Siirt and Çanakkale regions in Turkey.

\subsubsection{Data-Gathering Tools}

In this study the 'Scale of Attitudes towards Scientific Research' developed by Korkmaz, Şahin, and Yeşil (2011) and a questionnaire form were used as a data collection tool. This five-point Likert-type scale was made up of 30 items under four sub-dimensions: 'Reluctance to help researchers (B1)', "Negative attitude towards research (B2)", 'Positive attitude towards research (B3)' and 'Positive attitude towards researchers (B4)'. The validity and reliability coefficients of the scale change between 0.765 and 0,851 (Korkmaz, Şahin, \& Yeşil, 2011). In most research, a validity coefficient of at least 0.70 is accepted (McMillan \& Schumacher, 2010). Accordingly, this scale is considered to be reliable. Data was obtained through electronic survey on Google forms.

\subsubsection{Research Design}

This research was designed according to the descriptive survey model. Participant opinions were received about the current situation by collecting data without making any change in their current features. Descriptive methods are the methods aiming to describe a situation that existed in the past or still exist as they are. Therefore, as investigating the attitudes of students towards scientific research were aimed descriptive survey design was applied in this study.

\subsubsection{Analysis of Data}

Data obtained was analyzed with IBM SPSS 22.0 (Statistical Package for Social Sciences) for Windows. In data evaluation, while t-test was used for the comparison of quantitative continuous data between two independent groups, One Way Anova test was used for the comparison of quantitative continuous data between more than two independent groups. Tukey test was used as a complementary Post-Hoc analysis to determine the differences after the Anova test.

\section{Results}

In this section results determined through statistical analysis related to data obtained were given in tables. 
Table 1. Differentiation of sub-dimension scores of attitudes towards scientific research scale according to gender variable

\begin{tabular}{|c|c|c|c|c|c|c|c|}
\hline & Gender & $\mathrm{N}$ & Mean Rank & $\mathrm{s}$ & sd & $\mathrm{t}$ & $\mathrm{p}$ \\
\hline \multirow{2}{*}{ Unwilling For Helping Researchers } & Male & 208 & 21.48 & 7.10 & .358 & 3.04 & .00 \\
\hline & Female & 152 & 19.32 & 5.99 & & & \\
\hline \multirow{2}{*}{ Negative Attitude Towards Research } & Male & 208 & 20.88 & 7.27 & & 3,86 & .00 \\
\hline & Female & 152 & 18.18 & 5.34 & & & \\
\hline \multirow{2}{*}{ Positive Attitude Towards Research } & Male & 208 & 26.14 & 5.32 & & -.26 & .79 \\
\hline & Female & 152 & 26.28 & 4.93 & & & \\
\hline \multirow{2}{*}{ Positive Attitude Towards Researchers } & Male & 208 & 24.39 & 4.29 & & -.67 & .50 \\
\hline & Female & 152 & 24.69 & 4.08 & & & \\
\hline
\end{tabular}

In Table 1 when sub-dimension scores in the scale of attitudes towards scientific research were examined according to gender variables; a significant difference in male participants was determined in 'unwillingness for helping researchers' and 'negative attitude towards research' sub-dimensions $(\mathrm{p}<0.05)$. However, there were no significant differences in 'positive attitude towards research' and 'positive attitude towards researchers' sub-dimensions $(\mathrm{p}>0.05)$.

Table 2. Differentiation of sub-dimension scores of attitudes towards scientific research scale according to age variable

\begin{tabular}{|c|c|c|c|c|c|c|c|}
\hline & Age & $\mathrm{N}$ & Mean Rank & $\mathrm{s}$ & sd & $\mathrm{t}$ & $\mathrm{p}$ \\
\hline \multirow{2}{*}{ Unwilling For Helping Researchers } & 21 Age and Below & 194 & 21.15 & 6.47 & .358 & 1.77 & .08 \\
\hline & 22 Age and Above & 166 & 19.89 & 6.97 & & & \\
\hline \multirow{2}{*}{ Negative Attitude Towards Research } & 21 Age and Below & 194 & 20.18 & 6.84 & & 1.36 & .17 \\
\hline & 22 Age and Above & 166 & 19.22 & 6.42 & & & \\
\hline \multirow{2}{*}{ Positive Attitude Towards Research } & 21 Age and Below & 194 & 25.94 & 5.14 & & -1.02 & .31 \\
\hline & 22 Age and Above & 166 & 26.50 & 5.16 & & & \\
\hline \multirow{2}{*}{ Positive Attitude Towards Researchers } & 21 Age and Below & 194 & 24.40 & 4.13 & & -.58 & .56 \\
\hline & 22 Age and Above & 166 & 24.66 & 4.28 & & & \\
\hline
\end{tabular}

In Table 2, when differentiation status in sub-dimension scores of participants in the scale of attitudes towards scientific research was examined there was not any significant difference according to age variable ( $>0.05)$.

Table 3. Differentiation of sub-dimension scores of attitudes towards scientific research scale according to intention of becoming an academician variable

\begin{tabular}{|c|c|c|c|c|c|c|c|}
\hline & Intention of Becoming an Academician & $\mathrm{N}$ & Mean Rank & $\mathrm{s}$ & $\mathrm{sd}$ & $\mathrm{t}$ & $\mathrm{P}$ \\
\hline \multirow{2}{*}{ Unwilling For Helping Researchers } & Yes & 221 & 20.20 & 6.81 & .358 & -1.30 & .19 \\
\hline & No & 139 & 21.15 & 6.58 & & & \\
\hline \multirow{2}{*}{ Negative Attitude Towards Research } & Yes & 221 & 19.31 & 6.38 & & -1.55 & .12 \\
\hline & No & 139 & 20.42 & 7.05 & & & \\
\hline \multirow{2}{*}{ Positive Attitude Towards Research } & Yes & 221 & 27.42 & 4.86 & & 5.94 & .00 \\
\hline & No & 139 & 24.26 & 5.02 & & & \\
\hline \multirow{2}{*}{ Positive Attitude Towards Researchers } & Yes & 221 & 24.98 & 4.04 & & 2.67 & .01 \\
\hline & No & 139 & 23.78 & 4.35 & & & \\
\hline
\end{tabular}

In Table 3, when sub-dimension scores in the scale of attitudes towards scientific research were examined according to intention for becoming an academician variable; there were no significant differences in 'unwillingness for helping researchers' and 'negative attitude towards research' sub-dimensions ( $\mathrm{p}>0.05)$. However, there were significant differences in sub-dimensions of 'positive attitude towards research' and 'positive attitude towards researchers' for those who had the intention to become an academician $(p<0.05)$. 
Table 4. Differentiation of sub-dimension scores of attitudes towards scientific research scale according to province where faculty located variable

\begin{tabular}{|c|c|c|c|c|c|c|c|}
\hline & & $\begin{array}{l}\text { Sum of } \\
\text { Squares }\end{array}$ & df & Mean Square & $\mathrm{F}$ & $\mathrm{p}$ & $\begin{array}{l}\text { Source of } \\
\text { Difference }\end{array}$ \\
\hline \multirow{3}{*}{ Unwilling For Helping Researchers } & Inter Group & 127.63 & 5.00 & 25.53 & .56 & .73 & \\
\hline & Intra Group & 16124.63 & 354.00 & 45.55 & & & \\
\hline & Total & 16252.26 & 359.00 & & & & \\
\hline \multirow{3}{*}{ Negative Attitude Towards Research } & Inter Group & 348.76 & 5.00 & 69.75 & 1.59 & .16 & \\
\hline & Intra Group & 15554.70 & 354.00 & 43.94 & & & \\
\hline & Total & 15903.46 & 359.00 & & & & \\
\hline \multirow{3}{*}{ Positive Attitude Towards Research } & Inter Group & 557.87 & 5.00 & 111.57 & 4.41 & .00 & $\begin{array}{c}\mathrm{B}>\mathrm{F} \\
\mathrm{F}>\mathrm{A}-\mathrm{C}\end{array}$ \\
\hline & Intra Group & 8957.73 & 354.00 & 25.30 & & & \\
\hline & Total & 9515.60 & 359.00 & & & & \\
\hline \multirow{3}{*}{ Positive Attitude Towards Researchers } & Inter Group & 99.89 & 5.00 & 19.98 & 1.14 & .34 & \\
\hline & Intra Group & 6230.01 & 354.00 & 17.60 & & & \\
\hline & Total & 6329.90 & 359.00 & & & & \\
\hline
\end{tabular}

A: Çanakkale, B: Edirne, C: Rize, D: Diyarbakır, E:

Iğdır, F: Siirt

In Table 4, when sub-dimension scores in the scale of attitudes towards scientific research were examined there were no significant differences in "unwillingness for helping researchers" and "negative attitude towards research" and "positive attitude towards researchers" sub-dimensions according to the province where faculty located variable; $(\mathrm{p}>0.05)$. However, there was a significant difference in "positive attitude towards research" sub-dimension. As a result of Tukey test related to the source of difference; participants whose faculty were located in Edirne province had more positive attitudes towards research than those in Siirt and participants whose faculty located in Siirt were determined to have more positive attitudes than participants whose faculty located in Çanakkale and Rize provinces.

\section{Discussion and Conclusions}

In this study, attitudes of sports science faculty, students towards scientific research were discussed. In this sense differences between sub-dimension scores and demographical variables of attitudes of participants towards scientific research were examined and results obtained were discussed with similar studies in the literature. As there were four sub-dimensions in the scale used, each sub-dimension of the scale was evaluated in itself. The results obtained in this study and the relations of them with other studies were discussed below. When sub-dimension scores in the scale of attitudes towards scientific research were examined according to gender variables; a significant difference in male participants was determined in 'unwillingness for helping researchers' and 'negative attitude towards research' sub-dimensions. However, there were no significant differences in 'positive attitude towards research' and 'positive attitude towards researchers' sub-dimensions. As a society; as we live in a patriarchal structure, males are more involved in social life than females. And yet this causes male individuals to look for a job to keep their life up. For this reason, male students may tend to find a job quickly instead of following a long path like being a researcher. Therefore this may cause male individuals/students to be unwilling to research and researcher. However, Shaukat et al. (2014), in their study on graduate students' attitudes towards research; revealed that male students care about research as they associate research to life. These results contradict the results of the current study. This may be due to they see physical education and sports science jobs not requiring research as much as other faculties and departments. They want to doing the other aspects of their jobs rather than conducting research. Besides cultural differences like country, region, etc. may play a role in it. Polat (2014), in his study on education faculty students' attitudes towards scientific research, he found that there was a significant difference in positive attitude dimension towards research on behalf of male students. Therefore the reason why sports science faculty male students have lower positive attitudes towards scientific research than education faculty students may be due to they have more applied courses than education faculty students. In their study İlhan, Çelik, and Aslan (2016) determined that female students had significantly more positive attitudes towards scientific research than male students in the general university student population. The results of this study show consistency with the data in the gender variable of the current study. This shows that female students may have more positive attitudes towards scientific research than male students in the general university student 
population. However, as data related to attitudes towards scientific research in gender variables differ, this situation did not turn out to be clear (Polat, 2014). When differentiation status in sub-dimension scores of participants in the scale of attitudes towards scientific research was examined there was not any significant difference according to age variable. Biçer, Bozkırlı, and $\operatorname{Er}$ (2013) found no significant difference between class levels and in the unwillingness to help researchers and positive attitude towards research sub-dimensions in their study on comparing prospective Turkish teachers' attitudes towards scientific research with class levels. In general as ages according to class levels change, this can be discussed as an age variable. In this sense, it can be suggested that the findings of Biçer, Bozkırlı, and Er (2013) correspond to findings of the current study. However, Polat (2014) determined that 4th-grade prospective teachers had more positive attitudes in helping researchers than underclasses. As underclass levels were not at the last stage of their formal education they may not care as much as 4th grades do. When we compare these findings with the current study, it can be suggested that 4th-grade students in education faculties may tend to use more research skills in their teaching life than sports science faculty students in all grades. Students who graduated from Sports science faculties generally become physical education teachers in Turkey. Also, physical education and sports course is a very compelling course by students. Therefore, carrying out a successful physical education course can only be provided through the physical education teachers who are scientifically good at their work (Aydoğan \& Baş, 2016). In this context attitudes of sports science faculty students towards scientific research may play an important role both as a physical education teacher and as a sports scientist. For this reason, the variable 'intention of becoming an academician in the future' was considered to be used in participants in the current study. In the literature review, there were no any variables to be seen particularly as "intention of becoming an academician" When results of the current study were examined there were significant differences in sub-dimensions of "positive attitude towards research" and "positive attitude towards researchers" for those who had the intention to become an academician. It can be suggested that the reason why sports science faculty students had more positive attitudes towards research and researchers is that students who had the intention of becoming an academician are more likely to have positive attitudes towards research and researchers. When accessible literature was examined, no studies were discussing the differentiation status of attitudes towards scientific research according to the province where faculty located variable. In this study, when sub-dimension scores in the scale of attitudes towards scientific research were examined, there was a significant difference in 'positive attitude towards research' sub-dimension. As a result of Tukey test related to the source of difference; participants whose faculty were located in Edirne province had more positive attitudes towards research than those in Siirt and participants whose faculty located in Siirt were determined to have more positive attitudes than participants whose faculty located in Çanakkale and Rize provinces. This may be due to university and faculties may differ regarding socio-cultural features and educational conditions.

\section{References}

Adams, N. A., \& Holcomb, W. R. (1986). Analysis of the relationship between anxiety about mathematics and performance. Psychological Reports, 59(2), 943-948. https://doi.org/10.2466/pr0.1986.59.2.943

Allport, G. W. (1935). Attitudes: A handbook of social psychology. Clark University Press, Worcester.

Aydoğan, H., \& Baş, M., (2016). Examining motivation of teacher candidates to become a teacher International Journal of Sports. Exercise and Training Studies, 2(3), 112-124. https://doi.org/10.18826/ijsets.83797

Berryman, J., \& Park, R. (1992). Sport and Exercise Science (pp. 14-19). Urbana and Chicago: University of Illinois Press.

Biçer, N., Bozkırlı, K., \& Er, O. (2013). Evaluation of Attitudes Towards Scientific research of Turkish Language Prospective Teachers. Journal of Turkish Research, 50, 327-341. https://doi.org/10.14222/Turkiyat33

Çelik, S., Önder, G., Durmaz, K., Yurdusever, Y., \& Uysal, N. (2014). Determination of anxiety and attitude towards doing scientific research of nursing students. Journal of Health Science and Profession-HSP, 1(2), 23-31. https://doi.org/10.17681/hsp.46332

İlhan, A., Çelik, H. C., \& Aslan, A. (2016). Evaluating the attitudes of university students about scientific research. İönü University Journal of the Faculty of Education, 17(2), 141-156. https://doi.org/10.17679/iuefd.17218132

Korkmaz, Ö., Şahin, A., \& Yeşil, R. (2011). Study of Validity and Reliability of Scale of Attitude towards Scientific Research. Primary School Online, 10(3), 961-973.

McMillan, J. H., \& Schumacher, S. (2010). Research in Education: Evidence-Based Inquiry, MyEducationLab Series. Pearson.

Polat, M. (2014). Students' Attitudes towards Scientific Research in the Faculty of education. Pamukkale 
University Journal of Social Sciences Institute, 18, 77-90. https://doi.org/10.5505/pausbed.2014.51423

Şenyüzlü, E. (2013). Investigating The Effects of Exercise Participation on Aggressive Behaviors in University Students (Master's Thesis). Dumlupınar University Kütahya.

Shaukat, S., Siddiquah, A., Abiodullah, M., \& Akbar, R. A. (2014). Postgraduate Students' Attitudes towards Research. Bulletin of education and research, 36(1), 111-122.

Zan, R., \& Di Martino, P. (2007). Attitude toward mathematics: Overcoming the positive/negative dichotomy. The Montana Mathematics Enthusiast, 3(1), 157-168.

\section{Copyrights}

Copyright for this article is retained by the author(s), with first publication rights granted to the journal.

This is an open-access article distributed under the terms and conditions of the Creative Commons Attribution license (http://creativecommons.org/licenses/by/4.0/). 